\title{
Produtividade de grãos, adaptabilidade e estabilidade de genótipos de soja de ciclos precoce e médio
}

\author{
Grains productivity, adaptability and stability of earlier and \\ medium cycles of soybean genotypes
}

\author{
Edmar Soares de Vasconcelos ${ }^{1 *}$; Múcio Silva Reis ${ }^{2}$; \\ Tuneo Sediyama ${ }^{2}$; Cosme Damião $\mathrm{Cruz}^{3}$
}

\begin{abstract}
Resumo
O trabalho foi desenvolvido com objetivo de avaliar a produtividade de grãos, a adaptabilidade e estabilidade fenotípica de cultivares e linhagens de soja de ciclos precoce e médio. Os ensaios foram conduzidos em Viçosa, Florestal, São Gotardo e Rio Paranaíba, no Estado de Minas Gerais, em dois anos agrícolas. Utilizou-se o delineamento experimental em blocos completos com as cultivares e linhagens de soja distribuídas ao acaso, com quatro repetições. Foram obtidos os índices de rendimento relativo aos padrões (cultivares) e empregados os métodos de Annicchiarico e Centróide para análise da adaptabilidade e estabilidade fenotípica. A interação genótipos, locais e anos (GxLxA) para produtividade de grãos foi significativa e, com base no $\mathrm{R}^{2}$, detectou-se que o comportamento diferencial dos genótipos em relação aos locais $\left(\mathrm{R}^{2}=50,17 \%\right)$ foi mais pronunciado do que em relação aos anos agrícolas $\left(\mathrm{R}^{2}=13,81 \%\right)$. A linhagem CS 801 apresentou adaptabilidade à ambientes de alta tecnologia, superando inclusive a produtividade dos cultivares padrões utilizados. As cultivares CAC-1, UFV-16, UFV-19 e as linhagens CS 801, CS 802 e UFV98 700739 foram classificadas como de adaptabilidade geral.
\end{abstract}

Palavras-chave: Linhagens, produção de grãos, interação genótipos ambientes, annicchiarico, centróide

\begin{abstract}
The work was developed with objective of evaluate the grain yield, the adaptability and phenotypic stability of soybean cultivars and lineages with earlier and medium cycles. The experiments were carried out in Viçosa, Florestal, São Gotardo and Rio Paranaíba, in the Minas Gerais State, in two agricultural years. We used the experimental design of blocks completely with treatments allocate at random, in four repetitions. Wasobtain the production relative index to the patterns (cultivar) and employed the Annicchiarico and Centroid methods for adaptability and stability fenotipic analyzes. The genotypes $\mathrm{x}$ environments $\mathrm{x}$ crop seasonsinteraction (GxLxA) for yield grains was significant and, for the $\mathrm{R}^{2}$, it was detected that the differential performance of the genotypes in relation to the environments $(\mathrm{R} 2=50,17 \%)$ it was bigger than in to the crop seasons $(\mathrm{R} 2=13,81 \%)$. The lineage CS 801 showed adaptability to high-tech environments, surpassing the productivity of standards cultivars used. The CAC-1, UFV-16, UFV-19 cultivars and CS 801, CS 802 and UFV98 700,739 lineage were classified as general adaptability.
\end{abstract}

Key words: Lineages, grains productions, genotypes environments interaction, annicchiarico, centróide

1 Prof., Dept ${ }^{\circ}$ de Agronomia, Centro de Ciências Agrárias, Universidade Estadual do Oeste do Paraná, UNIOESTE, Marechal Cândido Rondon, PR. E-mail: edmar.vasconcelos@unioeste.br

2 Profs., Dept ${ }^{\circ}$ de Fitotecnia, Centro de Ciências Agrárias, Universidade Federal de Viçosa, UFV, Viçosa, MG. E-mail: msreis@ ufv.br; tuneo@ufv.br

3 Prof., Dept ${ }^{\circ}$ de Biologia Geral, Centro de Ciências Biológicas, UFV, Viçosa, MG. E-mail: cdcruz@ufv.br

* Autor para correspondência 


\section{Introdução}

A soja (Glycine $\max$ (L.) Merrill), uma das principais oleaginosas produzidas no mundo, é matéria prima empregada na elaboração de diversos produtos, desde óleo até papel. Essa leguminosa, em função de seu valor econômico e de sua potencialidade de cultivo em diversas condições, tem apresentado constante desenvolvimento tecnológico, o que permitiu, entre outras coisas, aumento significativo de sua produtividade e expansão de fronteiras agrícolas (OLIVEIRA et al., 2005). Os programas de melhoramento de soja exerceram influência marcante sobre o desenvolvimento dessa cultura no Brasil.

No caso dos programas de melhoramento de soja, o principal objetivo é aumentar a produtividade, para que o sojicultor possa auferir maiores lucros, sem a necessidade de investimentos adicionais, quanto a outros fatores de produção. Ao mesmo tempo, busca-se aumentar a capacidade adaptativa dos cultivares em relação ao clima e ao solo, a resistência a doenças e pragas e, também, melhorar a qualidade do óleo e da proteína dos grãos (ADULOJU; MAHAMOOD; ABAYOMI, 2009; VASCONCELOS, 2009; NASCIMENTO et al., 2010; GULLUOGLU; ARIOGLU; KURT, 2011).

$\mathrm{Na}$ condição da capacidade adaptativa, vale ressaltar que a soja é cultivada em várias regiões do mundo, numa grande diversidade de ambientes, o que afeta expressivamente a produtividade de grãos dos diferentes materiais genéticos existentes, originando com isso a interação genótipos por ambientes (GxA). Espera-se que essa interação assuma papel fundamental na manifestação fenotípica, devendo ser estimada e considerada na indicação de cultivares no programa de melhoramento genético (PRADO et al., 2001; BURATT et al, 2007; COLOMBARI FILHO et al., 2013).

Para conhecer a interação GxA existem inúmeros métodos, porém Silva e Duarte (2006) recomendam o emprego do método de Annicchiarico ou de Lin e Binns, uma vez que os mesmos são fortemente associados, não justificando o emprego de ambos. Outro método que tem sido empregado é o método do Centróide para análise da adaptabilidade que permite a análise dos genótipos possibilitando explorar melhor a interação genótipos por ambientes. Este método tendo sido empregado na análise de adaptabilidade em diferentes culturas como eucaliptus (ROCHA et al., 2005), soja (VASCONCELOS, 2006; PELÚZIO et al., 2008) e alfafa (VASCONCELOS et al., 2008), sendo modificado por Vasconcelos et al. (2011) para possibilitar melhor descrição da adaptabilidade e estabilidde fenotípica.

O método Integrado para análise da adaptabilidade e estabilidade fenotípica (VASCONCELOS et al., 2011), também conhecido como método do centróide modificado (NASCIMENTO et al., 2009), consiste da comparação de valores de distância cartesiana entre os genótipos avaliados e sete ideótipos (genótipos referência), estabelecidos com base nos dados experimentais. Esses ideótipos representam genótipos com adaptabilidade geral, específica a ambientes favoráveis, específica a ambientes desfavoráveis e genótipos poucos adaptados.

Este trabalho foi desenvolvido com objetivo de avaliar a produtividade de grãos, adaptabilidade e estabilidade fenotípica de cultivares e linhagens de soja de ciclos precoce e médio.

\section{Material e Métodos}

Neste trabalho foram avaliarados genótipos de soja, de ciclos precoce e médio, provenientes dos ensaios finais de avaliação do comportamento agronômico, do Programa de Melhoramento de Soja do Departamento de Fitotecnia da Universidade Federal de Viçosa, conduzidos no Estado de Minas Gerais, em dois anos agrícolas, 2006/2007 e 2007/2008. Os experimentos foram conduzidos em quatro locais: Viçosa, Florestal, São Gotardo e Rio Paranaíba, nos dois anos agrícolas.

A semeadura no ano de 2006 foi realizada nos 
dias 1, 2, 12 e 16 de dezembro em Viçosa, Florestal, São Gotardo e Rio Paranaíba, respectivamente. A semeadura no ano de 2007 foi realizada nos dias 9 e 29 de novembro, 12 e 16 de dezembro, em Viçosa, Florestal, São Gotardo e Rio Paranaíba, respectivamente.

Os experimentos receberam adubação de base com $250 \mathrm{~kg} \mathrm{ha}^{-1}$ do formulado 00-20-20 em todos os experimentos conduzidos no ano agrícola de 2006/2007. A mesma dose do mesmo formulado foi empregada no ano de 2007/2008, exceto para Florestal, em que foram aplicados $360 \mathrm{~kg} \mathrm{ha}^{-1}$ do adubo 00-20-20 como adubação de base, devido a recomendação baseada nos resultados da análise do solo.

Em cada experimento de campo, foi utilizado o delineamento experimental em blocos completos com os tratamentos distribuídos ao acaso, com quatro repetições. A parcela foi constituída de quatro linhas distanciadas $0,5 \mathrm{~m}$ entre si, com 5 $\mathrm{m}$ de comprimento. Foi realizado o desbaste das plantas de cada linha, visando deixar 14 plantas por metro linear. A produtividade dos genótiposfoi determinada a partir da produção da área útil de $4,0 \mathrm{~m}^{2}$, correspondente às duas linhas centrais, com $4 \mathrm{~m}$ de comprimento, pois desprezou-se 0,5 metro em cada extremidade da parcela. Os tratos culturais foram realizados sempre que necessário e de acordo com o desenvolvimento da cultura.

Os materiais genéticos avaliados foram às mesmas dez linhagens e quatro cultivares em todos os locais e anos: CAC 1; CS 741; CS 801; CS 802; Splendor; UFV 16; UFV 19; UFV Pop IV-15; UFV Pop IV-6; UFV Pop IV-8; UFV Pop V-15; UFV Pop V-7; UFV98 700739 e UFVS2002290.

Os resíduos obtidos da análise do caráter produção de grãos foram submetidos ao teste de normalidade (teste de Lilliefors), visando verificar a necessidade ou não de transformação. Foi realizadaa análise de variância individual dos dados para verificação da homogeneidade de variância (teste de Cochram), exigindo a transformação, ou não, do número de graus de liberdade do resíduo para a análise conjunta.

Para comparação entre as médias, utilizou-se o teste de Tukey a 5\% de probabilidade $(\mathrm{p}<0,05)$. Após comparação de médias, foi obtido o Índice de Diferenciação de Fasoulas para cada média por meio da seguinte expressão: $\mathrm{ID}_{\mathrm{i}}=200 \mathrm{M} /[\mathrm{N}$ (N 1)], para $i=1,2, \ldots, N$. Em que, $I_{i}$ corresponde ao índice de diferenciação de Fasoulas para cada média i; N o número de médias submetidas ao teste de médias; e, $\mathrm{M}$ o número de médias que o tratamento i superou estatisticamente pelo teste de médias. Foram obtidos os índices de rendimento relativos aos padrões (cultivares) utilizados.

Os experimentos foram analisados no esquema fatorial triplo, com 2 anos, 4 locais e 14 genótipos (2x4x14), envolvendo um sistema de análise conjunta. Para a análise da interação genótipos por ambientes foram designados como ambientes os dois anos agrícolas e os quatro locais, gerando oito ambientes distintos. Os experimentos conduzidos em Viçosa, Florestal, São Gotardoe Rio Paranaíba no ano agrícola de 2006/2007, geraram os ambientes um, dois, três e quatro, respectivamente. Os experimentos conduzidos em Viçosa, Florestal, São Gotardoe Rio Paranaíba no ano agrícola de 2007/2008, geraram os ambientes cinco, seis, sete e oito, respectivamente.

Para analisar a adaptabilidade e estabilidade, quanto à produção de grãos dos diferentes genótipos de soja frente às variações ambientais foram utilizados o método de Annicchiarico (1992) e o método do Centróide. As análises estatísticas foram processadas com o auxílio do aplicativo computacional "Genes” (CRUZ, 2006).

\section{Resultados e Discussão}

Os erros apresentaram distribuição normal pelo teste de Lilliefors possibilitando o emprego de analises paramétricas sem necessidade de transformação dos dados.Verificou-se homogeneidade de variância 
pelo método de Cochram, permitindo o emprego da análise de variância. A relação entre o maior e o menor quadrado médio do resíduo foi igual a 6,95 (Tabela
1), não exigindo o ajuste dos graus de liberdade do resíduo para a realização da análise conjunta dos experimentos (PIMENTEL-GOMES, 2009).

Tabela 1. Resumo da análise de variância conjunta dos dados de produtividade dos cultivares e linhagens de soja oriundas dos ensaios finais (EFIs) de ciclo Precoce/Médio, do programa de melhoramento de soja da UFV, conduzidos em diferentes localidades no Estado de Minas Gerais nos anos agrícolas 2006/2007 e 2007/2008.

\begin{tabular}{lcccc}
\hline Fontes de variação & GL & QM & $\begin{array}{c}\text { Probabilidade de } \\
\text { erro tipo I }\end{array}$ & $\mathrm{R}^{2}$ \\
\hline (Blocos/Ambientes)/Ano & 24 & 286974,10 & - & - \\
Genótipos (G) & 13 & $1747588,12^{\mathrm{NS}}$ & 0,07 & - \\
Anos Agrícolas (AA) & 1 & $222680595,20^{*}$ & 0,04 & - \\
Locais (L) & 3 & $139391257,77^{\mathrm{NS}}$ & 0,07 & - \\
G x AA & 13 & $619407,56^{\mathrm{NS}}$ & 0,34 & 13,81 \\
G x L & 39 & $749878,28^{\mathrm{NS}}$ & 0,15 & 50,17 \\
AA x L & 3 & $20164372,00^{* *}$ & 0,00 & - \\
G x L x AA & 39 & $538339,92^{* *}$ & 0,00 & 36,02 \\
Resíduo & 312 & 259617,90 & - & - \\
\hline Média & & & 2892,88 & \\
CV. (\%) & & $6,97,65$ & \\
Relação entre o maior e o menor QMResíduo & & & \\
\hline
\end{tabular}

NS - Não significativo pelo teste F; **,* - Significativo a 1 e $5 \%$ de probabilidade pelo teste $\mathrm{F}$, respectivamente. $\mathrm{R}^{2}-$ Valor da contribuição das referidas fontes de variação para a interação genótipos ambientes.

Fonte: Elaboração dos autores.

A análise de variância (Tabela 1) possibilitou verificar a existência de significância da interação entre anos, locais e genótipos, indicando que existe comportamento diferencial dos genótipos dentro de cada local e ano (ambientes). Com relação à produtividadedesoja, diferentes autores (CARVALHO et al., 2002; DIAS et al., 2009; PELÚZIO et al., 2010) verificaram a existência de interação entre genótipos e ambientes, atribuindo as causas dessa interação aos fatores fisiológicos, adaptativos e relativos à escala de mensuração das variáveis.

Os valores de $\mathrm{R}^{2}$ (Tabela 1 ) indicam a magnitude da interação genótipos $\mathrm{x}$ ambientes, sendo considerado ambientes como a associação dos diferentes anos agrícolas e os diferentes locais. A interação genótipos $\mathrm{x}$ ambientes foi decomposta em efeitos de genótipos $\mathrm{x}$ anos agrícolas, genótipos $\mathrm{x}$ locais e genótipos $\mathrm{x}$ locais $\mathrm{x}$ anos agrícolas, sendo quantificada cada uma delas. Dessa forma é possível verificar o quanto cada uma contribui para a interação genótipos $\mathrm{x}$ ambientes. Pelos resultados, a interação genótipos x locais x anos agrícolas (GxLxAA) contribuiu com 36,02\% para a interação genótipos $\mathrm{x}$ ambientes, sendo exigido o seu estudo pormenorizado. Verificou-se ainda que a interação genótipos $x$ locais contribuiu mais que a interação genótipos $\mathrm{x}$ anos agrícolas para a interação genótipos x ambientes.

Como foi verificada existência da interação significativa entre genótipos, locais e anos (Tabela 1), o teste de média de Tukey foi realizado envolvendo os três fatores (Tabela 2). O teste de Tukey é muito empregado para a constatação da existência de diferenças entre os genótipos avaliados. Padovan et al. (2002), fazendo uso desse teste, conseguiram diferenciar genótipos de soja quanto a capacidade produtiva dos mesmos em Seropédica, no Estado do Rio de Janeiro. Silva, Lazarini e Eustáquio de Sá (2007) também fazendo uso do teste de Tukey, conseguiram discriminar genótipos de soja capazes de produzir sementes de alta qualidade no inverno, em Selvíria, Mato Grosso do Sul. 
Tabela 2. Valores médios da produtividade $\left(\mathrm{kg} \mathrm{ha}^{-1}\right)$, dos cultivares e linhagens de soja oriundas dos ensaios finais (EFIs) de ciclo Precoce/Médio, do programa de melhoramento de soja da UFV, conduzidos em diferentes localidades no Estado de Minas Gerais, nos anos agrícolas 2006/2007 e 2007/2008.

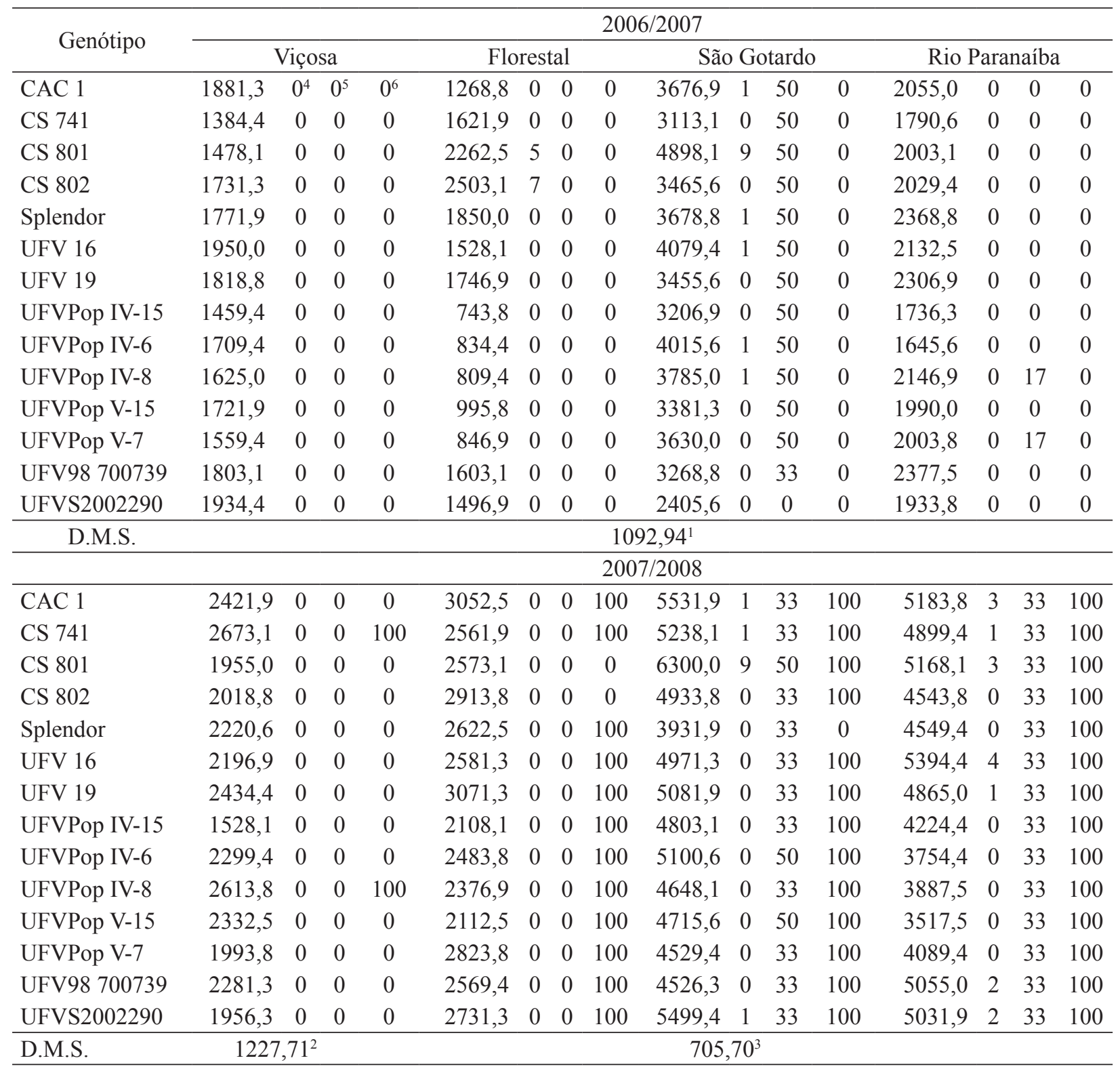

${ }^{1}$ - Diferença mínima significativa na comparação de médias, pelo teste de Tukey a 5\%, dos ambientes dentro de cada genótipo e ano; ${ }^{2}$ - Diferença mínima significativa na comparação de médias, pelo teste de Tukey a $5 \%$, dentro de cada local e ano; ${ }^{3}-$ Diferença mínima significativa na comparação de médias, pelo teste de Tukey a 5\%, dos anos, dentro de cada local e genótipo; ${ }^{4}$ - Resultados do teste de Fasoulas na comparação de médias, pelo teste de Tukey a 5\%, entre os genótipos de cada local e ano;

5 - Resultados do teste de Fasoulas na comparação de médias, pelo teste de Tukey a 5\%, entre os locais dentro de cada genótipo e ano; e, ${ }^{6}$ - Resultados do teste de Fasoulas na comparação de médias, pelo teste de Tukey a 5\%, entre os anos dentro de cada genótipo e local.

Fonte: Elaboração dos autores. 
$\mathrm{Na}$ comparação dos genótipos dentro de cada local e ano (Tabela 2), não se verificou diferença de produtividade entre os genótipos avaliados em Viçosa e Rio Paranaíba no ano agrícola de 2006/2007 e nem em Viçosa e Florestal no ano agrícola de 2007/2008. Em Florestal (2006/2007) a linhagem CS 802 foi a única a apresentar Índice de Diferenciação igual a sete (7), superando maior número de genótipos em produtividade, sendo considerada como a linhagem que superou a produtividade média das demais nesse referido local.

Em São Gotardo, nos anos agrícolas de 2006/2007 e 2007/2008 (Tabela 2), a linhagem CS 801 apresentou Índice de Diferenciação igual a nove (9), superando maior número de genótipos em produtividade, sendo considerada como a linhagem que superou a produtividade média das demais nesse referido local. Com relação à Rio Paranaíba, no ano agrícola 2007/2008, o material que apresentou esse comportamento, ou seja, primeiro colocado em produtividade, foi o cultivar UFV 16, superando a produtividade de quatro outros genótipos $(p<0,05)$.

Com relação aos locais de avaliação (Tabela 2), São Gotardo apresentou, de maneira geral, condições melhores para produtividade dos genótipos avaliados, gerando assim maiores médias de produtividade dos genótipos, tanto em 2006/2007 quanto em 2007/2008. No segundo ano de condução dos experimentos Rio Paranaíba também apresentou condições suficientes para que a maioria dos genótipos pudesse expressar seu potencial produtivo.

O ano agrícola 2007/2008 propiciou maior produtividade para os genótipos avaliados em cada ambiente (Tabela 2), exceto para Viçosa, em que as condições foram melhores para poucos genótipos (CS 741 e UFV Pop IV-8). Em Florestal, os genótipos CS 801 e CS 802 tiveram as mesmas produções em ambos os anos agrícolas avaliados. Em São Gotardo apenas Splendor teve produtividade semelhante para os anos agrícolas de 2006/2007 e 2007/2008.

O índice de rendimento relativo vem sendo empregado para melhor representar a superioridade de um material genético sobre um padrão, ou um cultivar utilizada como tal (HAMAWAKI et al., 2007). Na Tabela 3 estão dispostos os índices relativos obtidos no ano agrícola de 2006/2007 para cada um dos quatro padrões utilizados.

Em Viçosa, a linhagem que superou a maioria dos padrões foi UFVS2002290, tendo índice relativo de produtividade com valor menor que cem apenas em relação o cultivar UFV16, porém com valor próximo de cem, indicando pouca diferença entre suas produtividades.

Em Florestal as linhagens CS 801 e CS 802 apresentaram índice de rendimento relativo maiores que cem para todos os padrões utilizados, o que significa que essas linhagens superaram a produtividade dos padrões. A linhagem CS 801 também superou todos os padrões em São Gotardo. Em Rio Paranaíba, apenas a linhagem UFV98 700739 superou todos os padrões utilizados, quanto à produtividade, tendo índice de rendimento relativo maior que cem para todos eles (Tabela 3 ).

Pelos índices de rendimento relativo obtidos no ano agrícola de 2007/2008 (Tabela 4), apenas em Viçosa e São Gotardo algumas linhagens conseguiram superar todos os padrões quanto à produtividade. Em Viçosa, as linhagens CS 741 e UFVP IV-8 superaram todos os padrões; em São Gotardo apenas CS 801 superou os padrões em produtividade (Tabela 4). Miranda et al. (2003), trabalhando com diferentes materiais de soja, também verificaram linhagens com índices relativos de rendimento superiores aos dos cultivares padrões, evidenciando possível ganho genético (FARIA et al., 2007). 
Tabela 3. Índice de rendimento de grãos relativo das linhagens (em relação aos padrões) de soja oriundas dos ensaios finais (EFIs) de ciclo Precoce/Médio, do programa de melhoramento de soja da UFV, conduzidos em diferentes localidades no Estado de Minas Gerais no ano agrícola 2006/2007.

\begin{tabular}{|c|c|c|c|c|c|c|c|c|}
\hline \multirow{2}{*}{ Genótipo } & \multicolumn{4}{|c|}{ Viçosa } & \multicolumn{4}{|c|}{ Florestal } \\
\hline & CAC1 & Splendor & UFV16 & UFV19 & CAC1 & Splendor & UFV16 & UFV19 \\
\hline CAC 1 & 100,00 & 106,17 & 96,47 & 103,44 & 100,00 & 68,58 & 83,03 & 72,63 \\
\hline CS 741 & 73,59 & 78,13 & 70,99 & 76,12 & 127,83 & 87,67 & 106,13 & 92,84 \\
\hline CS 801 & 78,57 & 83,42 & 75,80 & 81,27 & 178,33 & 122,30 & 148,06 & 129,52 \\
\hline CS 802 & 92,03 & 97,71 & 88,78 & 95,19 & 197,29 & 135,30 & 163,80 & 143,29 \\
\hline Splendor & 94,19 & 100,00 & 90,87 & 97,42 & 145,81 & 100,00 & 121,06 & 105,90 \\
\hline UFV 16 & 103,65 & 110,05 & 100,00 & 107,22 & 120,44 & 82,60 & 100,00 & 87,48 \\
\hline UFV 19 & 96,68 & 102,65 & 93,27 & 100,00 & 137,68 & 94,43 & 114,31 & 100,00 \\
\hline UFVPop IV-15 & 77,57 & 82,36 & 74,84 & 80,24 & 58,62 & 40,20 & 48,67 & 42,58 \\
\hline UFVPop IV-6 & 90,86 & 96,47 & 87,66 & 93,99 & 65,76 & 45,10 & 54,60 & 47,76 \\
\hline UFVPop IV-8 & 86,38 & 91,71 & 83,33 & 89,35 & 63,79 & 43,75 & 52,97 & 46,33 \\
\hline UFVPop V-15 & 91,53 & 97,18 & 88,30 & 94,67 & 78,48 & 53,82 & 65,16 & 57,00 \\
\hline UFVPop V-7 & 82,89 & 88,01 & 79,97 & 85,74 & 66,75 & 45,78 & 55,42 & 48,48 \\
\hline UFV98 700739 & 95,85 & 101,76 & 92,47 & 99,14 & 126,35 & 86,66 & 104,91 & 91,77 \\
\hline UFVS2002290 & 102,82 & 109,17 & 99,20 & 106,36 & 117,98 & 80,91 & 97,96 & 85,69 \\
\hline \multirow{2}{*}{ Genótipo } & \multicolumn{4}{|c|}{ São Gotardo } & \multicolumn{4}{|c|}{ Rio Paranaíba } \\
\hline & CAC1 & Splendor & UFV16 & UFV19 & CAC1 & Splendor & UFV16 & UFV19 \\
\hline CAC 1 & 100,00 & 99,95 & 90,13 & 106,40 & 100,00 & 86,75 & 96,37 & 89,08 \\
\hline CS 741 & 84,67 & 84,62 & 76,31 & 90,09 & 87,14 & 75,59 & 83,97 & 77,62 \\
\hline CS 801 & 133,21 & 133,15 & 120,07 & 141,74 & 97,48 & 84,56 & 93,93 & 86,83 \\
\hline CS 802 & 94,25 & 94,21 & 84,95 & 100,29 & 98,75 & 85,67 & 95,16 & 87,97 \\
\hline Splendor & 100,05 & 100,00 & 90,18 & 106,46 & 115,27 & 100,00 & 111,08 & 102,68 \\
\hline UFV 16 & 110,95 & 110,89 & 100,00 & 118,05 & 103,77 & 90,03 & 100,00 & 92,44 \\
\hline UFV 19 & 93,98 & 93,93 & 84,71 & 100,00 & 112,26 & 97,39 & 108,18 & 100,00 \\
\hline UFVPop IV-15 & 87,22 & 87,17 & 78,61 & 92,80 & 84,49 & 73,30 & 81,42 & 75,26 \\
\hline UFVPop IV-6 & 109,21 & 109,16 & 98,44 & 116,21 & 80,08 & 69,47 & 77,17 & 71,34 \\
\hline UFVPop IV-8 & 102,94 & 102,89 & 92,78 & 109,53 & 104,47 & 90,63 & 100,67 & 93,06 \\
\hline UFVPop V-15 & 91,96 & 91,91 & 82,89 & 97,85 & 96,84 & 84,01 & 93,32 & 86,26 \\
\hline UFVPop V-7 & 98,73 & 98,67 & 88,98 & 105,05 & 97,51 & 84,59 & 93,96 & 86,86 \\
\hline UFV98 700739 & 88,90 & 88,85 & 80,13 & 94,59 & 115,69 & 100,37 & 111,49 & 103,06 \\
\hline UFVS2002290 & 65,43 & 65,39 & 58,97 & 69,61 & 94,10 & 81,64 & 90,68 & 83,83 \\
\hline
\end{tabular}

Fonte: Elaboração dos autores.

Como foi verificada existência da interação entre genótipos e ambientes (locais e anos), realizouse a análise de adaptabilidade e estabilidade da produtividade de grãos pelo teste de Annicchiarico (Tabela 5) e pelo teste do Centróide para análise da adaptabilidade e estabilidade fenotípica (Tabela 6).

Dentre as linhagens avaliadas, a CS 801 apresentou índice de recomendação para ambientes favoráveis acima de 100, sendo assim adaptada às condições de ambientes favoráveis (Florestal e São Gotardo, nos ano agrícola 2007/2008). Vale ainda ressaltar que CS 801 teve, relativamente às demais, a primeira colocação quanto à produtividade. As linhagens CS 802 e UFV98 700739 apresentaram índice de recomendação para ambientes desfavoráveis acima de 100 (Tabela 5), sendo adaptadas às condições desfavoráveis (Viçosa, Florestal e São Gotardo em 2006/2007 e Viçosa em 2007/2008) pelo método de Annicchiarico (1992). 
Pelo método do Centróide a linhagem CS 801 foi classificada como de máxima adaptabilidade específica a ambientes favoráveis e estabilidade em ambientes desfavoráveis (Tabela 6). Enquanto que CS 802 apresentou máxima adaptabilidade específica a ambientes desfavoráveis e estabilidade em ambientes favoráveis. Os demais genótipos foram classificados como tendo máxima estabilidade fenotípica, resultando nos genótipos de maior adaptabilidade e estabilidade pelo método de Annicchiarico (1992).

Tabela 4. Índice de rendimento de grãos relativo das linhagens (em relação aos padrões) de soja oriundas dos ensaios finais (EFIs) de ciclo Precoce/Médio, do programa de melhoramento de soja da UFV, conduzidos em diferentes localidades no Estado de Minas Gerais no ano agrícola 2007/2008.

\begin{tabular}{|c|c|c|c|c|c|c|c|c|}
\hline \multirow{2}{*}{ Genótipo } & \multicolumn{4}{|c|}{ Viçosa } & \multicolumn{4}{|c|}{ Florestal } \\
\hline & CAC1 & Splendor & UFV16 & UFV19 & CAC1 & Splendor & UFV16 & UFV19 \\
\hline CAC 1 & 100,00 & 109,06 & 110,24 & 99,49 & 100,00 & 116,40 & 118,26 & 99,39 \\
\hline CS 741 & 110,37 & 120,38 & 121,68 & 109,81 & 83,93 & 97,69 & 99,25 & 83,41 \\
\hline CS 801 & 80,72 & 88,04 & 88,99 & 80,31 & 84,30 & 98,12 & 99,69 & 83,78 \\
\hline CS 802 & 83,35 & 90,91 & 91,89 & 82,93 & 95,45 & 111,11 & 112,88 & 94,87 \\
\hline Splendor & 91,69 & 100,00 & 101,08 & 91,22 & 85,91 & 100,00 & 101,60 & 85,39 \\
\hline UFV 16 & 90,71 & 98,93 & 100,00 & 90,24 & 84,56 & 98,43 & 100,00 & 84,05 \\
\hline UFV 19 & 100,52 & 109,63 & 110,81 & 100,00 & 100,61 & 117,11 & 118,98 & 100,00 \\
\hline UFVPop IV-15 & 63,10 & 68,82 & 69,56 & 62,77 & 69,06 & 80,39 & 81,67 & 68,64 \\
\hline UFVPop IV-6 & 94,94 & 103,55 & 104,67 & 94,45 & 81,37 & 94,71 & 96,22 & 80,87 \\
\hline UFVPop IV-8 & 107,92 & 117,70 & 118,98 & 107,37 & 77,87 & 90,63 & 92,08 & 77,39 \\
\hline UFVPop V-15 & 96,31 & 105,04 & 106,17 & 95,82 & 69,21 & 80,55 & 81,84 & 68,78 \\
\hline UFVPop V-7 & 82,32 & 89,78 & 90,75 & 81,90 & 92,51 & 107,67 & 109,39 & 91,94 \\
\hline UFV98 700739 & 94,19 & 102,73 & 103,84 & 93,71 & 84,17 & 97,97 & 99,54 & 83,66 \\
\hline UFVS2002290 & 80,77 & 88,09 & 89,05 & 80,36 & 89,48 & 104,15 & 105,81 & 88,93 \\
\hline \multirow{2}{*}{ Genótipo } & \multicolumn{4}{|c|}{ São Gotardo } & \multicolumn{4}{|c|}{ Rio Paranaíba } \\
\hline & CAC1 & Splendor & UFV16 & UFV19 & CAC1 & Splendor & UFV16 & UFV19 \\
\hline CAC 1 & 100,00 & 140,69 & 111,28 & 108,85 & 100,00 & 113,94 & 96,10 & 106,55 \\
\hline CS 741 & 94,69 & 133,22 & 105,37 & 103,07 & 94,51 & 107,69 & 90,82 & 100,71 \\
\hline CS 801 & 113,89 & 160,23 & 126,73 & 123,97 & 99,70 & 113,60 & 95,81 & 106,23 \\
\hline CS 802 & 89,19 & 125,48 & 99,25 & 97,09 & 87,65 & 99,88 & 84,23 & 93,40 \\
\hline Splendor & 71,08 & 100,00 & 79,09 & 77,37 & 87,76 & 100,00 & 84,34 & 93,51 \\
\hline UFV 16 & 89,87 & 126,43 & 100,00 & 97,82 & 104,06 & 118,57 & 100,00 & 110,88 \\
\hline UFV 19 & 91,87 & 129,25 & 102,23 & 100,00 & 93,85 & 106,94 & 90,19 & 100,00 \\
\hline UFVPop IV-15 & 86,83 & 122,16 & 96,62 & 94,51 & 81,49 & 92,86 & 78,31 & 86,83 \\
\hline UFVPop IV-6 & 92,20 & 129,73 & 102,60 & 100,37 & 72,43 & 82,53 & 69,60 & 77,17 \\
\hline UFVPop IV-8 & 84,02 & 118,22 & 93,50 & 91,46 & 74,99 & 85,45 & 72,07 & 79,91 \\
\hline UFVPop V-15 & 85,24 & 119,93 & 94,86 & 92,79 & 67,86 & 77,32 & 65,21 & 72,30 \\
\hline UFVPop V-7 & 81,88 & 115,20 & 91,11 & 89,13 & 78,89 & 89,89 & 75,81 & 84,06 \\
\hline UFV98 700739 & 81,82 & 115,12 & 91,05 & 89,07 & 97,52 & 111,11 & 93,71 & 103,91 \\
\hline UFVS2002290 & 99,41 & 139,87 & 110,62 & 108,22 & 97,07 & 110,61 & 93,28 & 103,43 \\
\hline
\end{tabular}

Fonte: Elaboração dos autores. 
Barros et al. (2008), trabalhando com genótipos de soja em Rondonópolis, Campo Verde, Nova Brasilândia e Vera, no Estado do Mato Grosso, verificaram que as metodologias de Lin e Binns, Annicchiarico e Centróide são coerentes entre si e permitiram identificar, entre os genótipos avaliados, os de maior produtividade e adaptabilidade. Silva e Duarte (2006) recomendam o emprego do método de Annicchiarico para análise da adaptabilidade e estabilidade fenotípica em soja, sendo esse método fortemente associado ao método de Lin e Binns para análise da interação genótipos por ambientes.

Os dados obtidos no presente trabalho quando submetidos às metodologias de Annicchiarico e
Centróide também apontaram a linhagem CS 801 como de melhor adaptabilidade e estabilidade fenotípica aos ambientes avaliados. Assim, os métodos de Annicchiarico e Centróide também foram coerentes entre si, possibilitando indicar esse genótipo como de melhor comportamento.

A linhagem CS 801 apresentou elevada média, superando inclusive os cultivares padrões, em alguns locais de avaliação, e adaptabilidade e estabilidade fenotípica em condições favoráveis. Assim é uma linhagem recomendável para cultivo em condições de ambientes favoráveis, na prática isso significa ambiente de elevados investimentos, em Minas Gerais.

Tabela 5. Adaptabilidade e estabilidade fenotípica da produtividade de grãos $\left(\mathrm{kg} \mathrm{ha}^{-1}\right)$ de cultivares e linhagens de soja oriundas dos ensaios finais (EFIs) de ciclo Precoce/Médio, do programa de melhoramento de soja da UFV, conduzidos em diferentes localidades no Estado de Minas Gerais nos anos agrícolas 2006/2007 e 2007/2008, pelo método de Annicchiarico.

\begin{tabular}{lcrrr}
\hline \multirow{2}{*}{ Genótipos } & Produtividade & \multicolumn{3}{c}{ Índice de Recomendação para ambientes $\left(\omega_{\mathrm{i}}\right)$} \\
\cline { 3 - 5 } & Média & Geral & Desfavorável & Favorável \\
\hline CAC 1 & 3133,98 & 104,16 & 102,22 & 107,48 \\
CS 741 & 2910,31 & 96,23 & 95,69 & 96,67 \\
CS 801 & 3329,77 & 106,33 & 97,91 & 122,04 \\
CS 802 & 3017,42 & 101,84 & 106,54 & 98,00 \\
Splendor & 2874,22 & 99,95 & 106,64 & 90,12 \\
UFV 16 & 3104,22 & 104,84 & 103,03 & 107,89 \\
UFV 19 & 3097,58 & 107,04 & 112,29 & 100,27 \\
UFV Pop IV-15 & 2476,25 & 77,39 & 70,60 & 91,81 \\
UFV Pop IV-6 & 2730,39 & 87,11 & 82,56 & 94,60 \\
UFV Pop IV-8 & 2736,56 & 88,76 & 86,96 & 91,73 \\
UFV Pop V-15 & 2595,88 & 86,55 & 86,74 & 85,81 \\
UFV Pop V-7 & 2684,53 & 87,12 & 84,41 & 92,03 \\
UFV98 700739 & 2935,55 & 100,95 & 105,21 & 94,46 \\
UFVS2002290 & 2873,67 & 94,96 & 98,53 & 89,03 \\
\hline
\end{tabular}

Fonte: Elaboração dos autores. 
Tabela 6. Adaptabilidade e estabilidade fenotípica da produtividade de grãos $\left(\mathrm{kg} \mathrm{ha}^{-1}\right)$ de cultivares e linhagens de soja oriundas dos ensaios finais (EFIs) de ciclo Precoce/Médio, do programa de melhoramento de soja da UFV, conduzidos em diferentes localidades no Estado de Minas Gerais nos anos agrícolas 2006/2007 e 2007/2008, pelo método do Centróide para análise da adaptabilidade e estabilidade fenotípica.

\begin{tabular}{|c|c|c|c|c|c|c|c|c|c|}
\hline \multirow{2}{*}{ Genótipos } & \multirow{2}{*}{$\begin{array}{l}\text { Produtividade } \\
\text { Média }\end{array}$} & \multirow{2}{*}{ Classe } & \multicolumn{7}{|c|}{ Probabilidade de pertencer a referida classe } \\
\hline & & & I & II & III & IV & $\mathrm{V}$ & VI & VII \\
\hline CAC 1 & 3133,98 & V & 0,13 & 0,12 & 0,09 & 0,08 & 0,26 & 0,16 & 0,16 \\
\hline CS 741 & 2910,31 & $\mathrm{~V}$ & 0,10 & 0,10 & 0,11 & 0,10 & 0,29 & 0,12 & 0,18 \\
\hline CS 801 & 3329,77 & VI & 0,23 & 0,15 & 0,06 & 0,06 & 0,12 & 0,27 & 0,11 \\
\hline CS 802 & 3017,42 & VII & 0,10 & 0,08 & 0,12 & 0,09 & 0,21 & 0,10 & 0,30 \\
\hline Splendor & 2874,22 & $\mathrm{~V}$ & 0,10 & 0,09 & 0,15 & 0,12 & 0,24 & 0,10 & 0,20 \\
\hline UFV 16 & 3104,22 & V & 0,13 & 0,12 & 0,09 & 0,08 & 0,26 & 0,16 & 0,16 \\
\hline UFV 19 & 3097,58 & V & 0,10 & 0,08 & 0,10 & 0,08 & 0,29 & 0,10 & 0,25 \\
\hline UFV Pop IV-15 & 2476,25 & V & 0,09 & 0,12 & 0,11 & 0,22 & 0,24 & 0,11 & 0,12 \\
\hline UFV Pop IV-6 & 2730,39 & $\mathrm{~V}$ & 0,10 & 0,13 & 0,11 & 0,14 & 0,25 & 0,13 & 0,14 \\
\hline UFV Pop IV-8 & 2736,56 & V & 0,10 & 0,11 & 0,12 & 0,15 & 0,27 & 0,11 & 0,15 \\
\hline UFV Pop V-15 & 2595,88 & V & 0,09 & 0,10 & 0,14 & 0,19 & 0,24 & 0,10 & 0,14 \\
\hline UFV Pop V-7 & 2684,53 & V & 0,09 & 0,10 & 0,12 & 0,16 & 0,29 & 0,11 & 0,14 \\
\hline UFV98 700739 & 2935,55 & $\mathrm{~V}$ & 0,09 & 0,09 & 0,12 & 0,11 & 0,30 & 0,10 & 0,19 \\
\hline UFVS2002290 & 2873,67 & V & 0,11 & 0,11 & 0,13 & 0,13 & 0,23 & 0,12 & 0,17 \\
\hline
\end{tabular}

Classe I: Adaptabilidade geral; Classe II: Adaptabilidade específica a ambientes favoráveis; Classe III: Adaptabilidade específica a ambientes desfavoráveis e Classe IV: Pouco adaptado; Classe V: Máxima estabilidade fenotípica; Classe VI: máxima adaptabilidade específica a ambientes favoráveis e estabilidade em ambientes desfavoráveis e Classe VII: máxima adaptabilidade específica a ambientes desfavoráveis e estabilidade em ambientes favoráveis.

Fonte: Elaboração dos autores.

\section{Conclusões}

O comportamento diferencial da produtividade dos genótipos avaliados em relação aos locais foi mais pronunciado do que em relação aos anos agrícolas.

A linhagem CS 801 apresentou adaptabilidade à ambientes de alta tecnologia, superando inclusive a produtividade dos cultivares padrões utilizados.

As cultivares CAC-1, UFV-16, UFV-19 e as linhagens CS 801, CS 802 e UFV98 700739 foram classificadas como de adaptabilidade geral.

\section{Referências}

ADULOJU, M. O.; MAHAMOOD, J.; ABAYOMI, Y. A. Evaluation of soybean [Glycine $\max (\mathrm{L})$ Merrill] genotypes for adaptability to a southern Guinea savanna environment with and without $\mathrm{P}$ fertilizer application in north central Nigeria. African Journal of Agricultural Research, Lagos, v. 4, n. 6, p. 556-563, 2009.
ANNICCHIARICO, P. Cultivar adaptation and recommendation from alfafa trials in Northern Italy. Journal of Genetics and Breeding, Islamabad, v. 46, n. 1, p. 269-278, 1992.

BARROS, H. B.; SEDIYAMA, T.; TEIXEIRA, R. de C.; CRUZ, C. D. Análises paramétricas e não-paramétricas para determinação da adaptabilidade e estabilidade de genótipos de soja. Scientia Agraria, Curitiba, v. 9, n. 3, p. 299-309, 2008.

BURATT, J. S.; MODA-CIRINO, V.; FONSECA JÚNIOR, N. da S.; PRETE, C. E. C.; FARIA, R. T. de. Adaptabilidade e estabilidade produtiva em genótipos precoces de feijão no estado do Paraná. Semina: Ciências Agrárias, Londrina, v. 28, n. 3, p. 373-380, 2007.

CARVALHO, C. G. P. de; ARIAS, C. A. A.; TOLEDO, J. F. F. de; ALMEIDA, L. A. de; KIIHL, R. A. de S.; OLIVEIRA, M. F. de. Interação genótipos x ambientes no desempenho produtivo da soja no Paraná. Pesquisa Agropecuária Brasileira, Brasília, v. 37, n. 7, p. 9891000, 2002. 
COLOMBARI FILHO, J. M.; RESENDE, M. D. V. de; MORAIS, O. P. de; CASTRO, A. P. de; GUIMARÃES, E. P.; PEREIRA, J. A.; UTUMI, M. M.; BRESEGHELLO, F. Uplandrice breeding in Brazil: a simultaneous genotypic evaluation of stability, adaptability and grain yield. Euphytica, Wageningen, v. 192, n. 1, p. 117-129, 2013.

CRUZ, C. D. Programa GENES: estatística experimental e matrizes. Viçosa: Universidade Federal de Viçosa, 2006. v. 1, 285 p.

DIAS, F. T. C.; PITOMBEIRA, J. B.; TEÓFILO, E. M.; BARBOSA, F. de S. Adaptabilidade e estabilidade fenotípica para o caráter rendimento de grãos em cultivares de soja para o Estado do Ceará. Revista Ciência Agronômica, Fortaleza, v. 40, n. 1, p. 129-134, 2009.

FARIA, A. P.; FONSECA JÚNIOR, N. da S.; DESTRO, D.; FARIA, R. T. de. Ganho genético na cultura da soja. Semina: Ciências Agrárias, Londrina, v. 28, n. 1, p. 7178, 2007.

GUlluOGlU, L.; ARIOGLU, H., KURT, C. Adaptability and stability of new soybean cultivars under double cropped conditions of Turkey. African Journal of Agricultural Research, Lagos, v. 6, n. 14, p. 3320-3325, 2011.

HAMAWAKI, O. T.; POLIZEL, A. C.; JULIATTI, F. C.; HAMAWAKI, R. L.; BRUNETTA, P. UFUS-Imperial: nova cultivar de soja para o Estado de Mato Grosso. Pesquisa Agropecuária Brasileira, Brasília, v. 42, n. 1, p. 137-139, 2007.

MIRANDA, M.A. C. de; BRAGA, N. R.; LOURENÇÃO, A. L.; MIRANDA, F. T. S. de; UNÊDA, S. H.; ITO, M. F. Descrição, produtividade e estabilidade da cultivar de soja IAC-24, resistente a insetos. Bragantia, Campinas, v. 62 , n. 1, p. 29-37, 2003.

NASCIMENTO, M.; CRUZ, C. D.; CAMPANA, A. C. M.; TOMAZ, R. S.; SALGADO, C. S.; FERREIRA, R. P. Alteração no método centroide de avaliação da adaptabilidade genotípica. Pesquisa Agropecuária Brasileira, Brasília, v. 44, n. 3, p. 263-269, 2009.

NASCIMENTO, M.; FINOTO, E. L.; SEDIYAMA, T.; CRUZ, C. D. Adaptability and stability of soybean in term so foil and protein content. Crop Breeding and Applied Biotechnology, Viçosa, v. 10, n. 1, p. 48-54, 2010.

OLIVEIRA, R. C. de; DI MAURO, A. O.; UNÊDATREVISOLI, S. H.; SANTOS, J. M. dos; OLIVEIRA, J. A. de; PERECIN, D.; ARANTES, N. E. Progênies superiores de soja resistentes ao tipo 3 do nematóide de cisto da soja. Pesquisa Agropecuária Brasileira, Brasília, v. 40, n. 8 , p. $745-751,2005$.
PADOVAN, M. P.; ALMEIDA, D. L. de; GUERRA, J. G. M., RIBEIRO, R. de L. D.; NDIAYE, A. Avaliação de cultivares de soja, sob manejo orgânico, para fins de adubação verde e produção de grãos, Pesquisa Agropecuária Brasileira, Brasília, v. 37, n. 12, p. 17051710, 2002.

PELÚZIO, J. M.; AFFÉRRI, F. S.; MONTEIRO, F. J. F.; MELO, A. V. de; PIMENTA, R. S. Adaptabilidade e estabilidade de cultivares de soja em várzea irrigada no Tocantins. Revista Ciência Agronômica, Fortaleza, v. 41, n. 3, p. 427-434, 2010.

PELÚZIO, J. M.; FIDELIS, R. R.; GIONGO, P.; SILVA, J. C. da; CAPPELLARI, D.; BARROS, H. B. Adaptabilidade e estabilidade de cultivares de soja em quatro épocas de semeadura no sul do Estado do Tocantins. Revista Ceres, Viçosa, MG, v. 55, n. 1, p. 3440, 2008.

PIMENTEL-GOMES, F. Curso de estatística experimental. 15. ed. Piracicaba: Fealq, 2009. 451 p.

PRADO, E. E. P.; HIRIMOTO, D. M.; GODINHO, V. P. C.; UTUMI, M. M.; RAMALHO, A. R. Adaptabilidade e estabilidade de cultivares de soja em cinco épocas de plantio no cerrado de Rondônia. Pesquisa Agropecuária Brasileira, Brasília, v. 36, n. 4, p. 625-635, 2001.

ROCHA, R. B.; MURO-ABAD, J. I.; ARAÚJO, E. F.; CRUZ, C. D. Avaliação do método do Centróide para estudo de adaptabilidade ao ambiente de clones de Eucalyptus grandis. Ciência Florestal, Santa Maria, v. 15, n. 3, p. 255-266, 2005.

SILVA, J. B. da; LAZARINI, E.; EUSTÁQUIO de SÁ, M. Avaliação de genótipos de soja em semeadura de inverno, em Selvíria, MS: produção e qualidade fisiológica de sementes. Revista Brasileira de Sementes, Brasília, v. 29, n. 3, p. 189-196, 2007.

SILVA, W. C. J. e; DUARTE, J. B. Métodos estatísticos para estudo de adaptabilidade e estabilidade fenotípica em soja. Pesquisa Agropecuária Brasileira, Brasília, v. 41, n. 1, p. 23-30, 2006.

VASCONCELOS, E. S. Avaliação da qualidade de sementes e estimativas de parâmetros genéticos e do padrão de resposta às variações ambientais, em soja [Glycinemax (L.) Merrill]. 2006. Dissertação (Mestrado em Genética e Melhoramento) - Universidade Federal de Viçosa, Viçosa, MG.

VASCONCELOS, E. S. Produtividade de grãos e padrão de resposta da soja às variações ambientais no estado de Minas Gerais. 2009. Tese (Doutorado em Genética e Melhoramento) - Universidade Federal de Viçosa, Viçosa, MG. 
VASCONCELOS, E. S. de; REIS, M. S.; CRUZ, C. VASCONCELOS, E. S; BARIONI JÚNIOR, W.; CRUZ, D.; SEDIYAMA, T.; SCAPIM, C. A. Integrated method for adaptability and phenotypic stability analysis. Acta Scientiarum. Agronomy, Maringá, v. 33, n. 2, p. 251-257, 2011.

C. D.; FERREIRA, R. de P.; RASSINI, J. B.; VILELA,

D. Seleção de genótipos de alfafa pela adaptabilidade e estabilidade da produção de matéria seca. Acta Scientiarum. Agronomy, Maringá, v. 30, n. 3, p. 339-343, 2008. 